\title{
Development and validation of a coupled numerical model for offshore floating multi-purpose platforms
}

\author{
L. Li \& M. Collu \& Y. Gao \\ Department of Naval Architecture, Ocean and Marine Engineering, University of Strathclyde, Glasgow, UK \\ C. Ruzzo \& F. Arena \\ Natural Ocean Engineering Laboratory, Mediterranea University of Reggio Calabria, Reggio Calabria, Italy \\ F. Taruffi \& S. Muggiasca \& M. Belloli \\ Department of Mechanical Engineering, Politecnico di Milano, Milan, Italy
}

\begin{abstract}
A multi-purpose platform (MPP) is an offshore system designed to serve the purposes of more than one offshore industry. Over the past decades, a number of industries have expanded or are expanding, from onshore to offshore locations. In the present work, the MPP proposed in the framework of Blue Growth Farm project is considered. The aim here is to develop and validate a coupled aero-hydro-servo-elastic numerical model, which will be used to predict the dynamic response of the MPP under a wide range of environmental conditions. Model test research was conducted to validate the developed numerical model. The model test was carried out in the water basin at Centrale Nantes, employing the Froude scale strategy. An innovative approach to modelling wind load in the experimental environment was proposed and applied. This paper reports the up-to-date research outcome of the Blue Growth Farm project - numerical model development and validation.
\end{abstract}

\section{INTRODUCTION}

The "blue growth" economy, already in 2012, represented 5.4 million jobs in Europe, generating a gross added value of 500 billion euros/year (European Commission, 2012). Apart from the mature activities (short sea shipping, oil and gas, coastline tourism, etc.), the ocean is providing new opportunities, in terms of aquatic products, renewable energy and maritime monitoring (European Commission, 2012). The research community has concentrated on these new opportunities for a long time.

Multi-purpose offshore structures for ocean resource exploitation have been investigated numerically in previous works. Muliawan et al. (2013) combined the OC3 Hywind and a wave energy converter to propose the STC concept. Cheng et al. developed a coupled model for the dynamics of a combined floating vertical axis wind turbine and wave energy converter concept. Li et al. (2018c) proposed a hybrid offshore renewable energy system HWNC, which combines a floating wind turbine, a wave energy converter and two tidal turbines. They further investigated the ultimate and fatigue limit states of the HWNC (Li et al., 2018a, Li et al., 2019b).

Although a series of numerical models have been developed, the validations of these tools still rely on comparative code-to-code check analysis due to the lack of reliable model test results. Wan et al. (2016) conducted an experimental study on the STC concept during operational state. Mode test research on a floating wind turbine was reported by $\mathrm{Li}$ et al. (2018b), where an improved thrust force modelling approach was proposed.

The academic and industrial significance of multi-purpose platforms are being recognized by the offshore engineering sector, and the European Commission starts to fund relevant research. The H2Ocean aimed to develop an innovative design for an economically and environmentally sustainable multi-use open-sea platform (H2Ocean, 2012). The MERMAID project developed concepts for the next generation of offshore platforms which can be used for multiple purposes (MERMAID, 2014). Other relevant projects include TROPOS (Tropos, 2012), Space@Sea (Space@Sea, 2017), MUSES (MUSES, 2016), etc. More recently, the 'Blue Growth Farm' project has been initiated in order to ensure the integrated, sustainable and ecological exploitation of open sea resources, by developing a multi-purpose offshore platform. This platform aims to integrate wind and wave energy devices (renewable energy generation), maritime surveillance unit (provide meteorological and oceanographic data) and docking system (accommodate specialized vessels).

This work presents the research outcome of the Blue Growth Farm project - development and validation of an aero-hydro-servo-elastic coupled numerical model. The coupled numerical model is developed on the basis of previous work (Li et al., 2019a, Ruzzo et al., 2019) with the addition of control and structural dynamics modules. A Froude 
scaled model test has been conducted to validate the developed coupled model. The structure of this research is outlined as follows. First, the main characteristics of the MPP is briefly introduced. Afterward, the development of the coupled model and the model test setup are interpreted in detail. Finally, this paper presents a preliminary validation of the coupled model

\section{MULTI-PURPOSE PLATFORM}

\subsection{Main characteristics}

Figure 1 sketches the multi-purpose platform considered in the present research, which is a simplified draft proposed in the Blue Growth Farm. Please note that the current model should not be taken as representative of its final design. The main infrastructure is a floating platform with an inner water pool. The platform is based on industrialized modular concrete caissons technology for typical marine applications. Due to the modular composition of the concrete caissons, each module in the installation bay will be connected rigidly to each other before it is moved by tugs up to the final destination site. Details of the structure construction are reported in (Lagasco et al., 2019). To meet all the platform's own energy needs and to export the excess energy to the onshore grid, the DTU $10 \mathrm{MW}$ wind turbine (Bak et al., 2013) and a number of oscillating-water-column (OWC) wave energy converters (WECs) based on the REWEC3 patent (Malara et al., 2017) are equipped. Two cranes and several other docking equipment are also installed on the port and starboard respectively to support the regular maintenance so that the facility can be used as a sea-based recharging station.

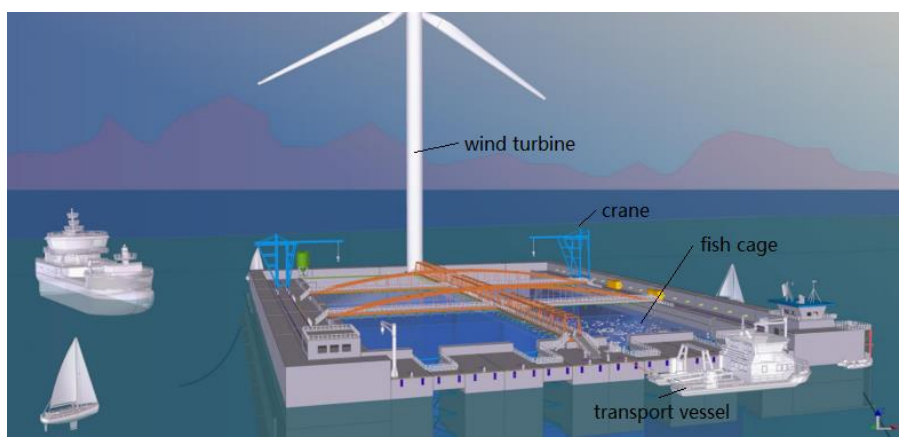

Figure 1. Sketch of the multi-purpose platform.

Table 1 summarizes some critical characteristics of the multi-purpose platform. The main size of the platform is $210 \mathrm{~m} \times 148 \mathrm{~m}$ and the inner water pool has a dimension of $172 \mathrm{~m} \times 124 \mathrm{~m}$. The designed draft is $20 \mathrm{~m}$. The large deck area and buoyancy volume allow the platform to carry a set of equipment.
Table 1 Main characteristics of the platform

\begin{tabular}{ll}
\hline Item & Value \\
\hline Platform size & $210 \mathrm{~m} \times 148 \mathrm{~m}$ \\
Inner pool size & $172 \mathrm{~m} \times 124 \mathrm{~m}$ \\
Draft & $20 \mathrm{~m}$ \\
Platform Mass & $2.13 \times 10^{8} \mathrm{~kg}$ \\
$\mathrm{I}_{\mathrm{xx}}$ & $7.28 \times 10^{11} \mathrm{~kg} \cdot \mathrm{m}^{2}$ \\
$\mathrm{I}_{\mathrm{yy}}$ & $1.09 \times 10^{12} \mathrm{~kg} \cdot \mathrm{m}^{2}$ \\
$\mathrm{I}_{\mathrm{zz}}$ & $1.80 \times 10^{12} \mathrm{~kg} \cdot \mathrm{m}^{2}$ \\
\hline
\end{tabular}

The platform is moored with 12 catenary lines, each 3 are connected to one corner. Table 2 gives the main mooring line properties

Table 2 Mooring line properties

\begin{tabular}{ll}
\hline Item & Value \\
\hline Line length & $815 \mathrm{~m}$ \\
Mass per unit length & $401 \mathrm{~kg} / \mathrm{m}$ \\
Diameter & $0.064 \mathrm{~m}$ \\
Axial stiffness & $1.722 \mathrm{e}+06 \mathrm{kN}$ \\
\hline
\end{tabular}

\section{MODELLING APPROACH}

Given the large size $(210 \mathrm{~m} \times 148 \mathrm{~m})$, the hydroelastic dynamics of the platform should be considered but, as demonstrated in previous investigation (Ruzzo et al., 2019), its impact on the global response can be considered as negligible at first approximation. Consequently, it is acceptable to treat the platform as a rigid body. The coupled model, as shown in Figure 2, is developed in Sima developed by DNV GL.

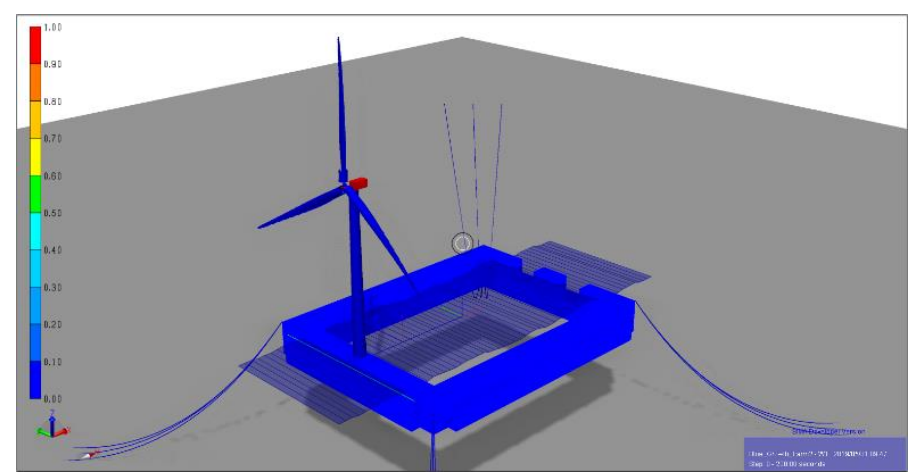

Figure 2. Sketch of the coupled model.

\subsection{Kinetics}

The kinetics of the multi-purpose platform is given by

$$
\begin{aligned}
& P^{\prime}+w \times P=F \\
& L^{\prime}+w \times L+v \times P=M
\end{aligned}
$$

where $\boldsymbol{F}$ and $\boldsymbol{M}$ are the external force and moment vectors, respectively. In the present research, they are the resultant loads of wind and wave. ' denotes the time derivatives. $\boldsymbol{P}$ and $\boldsymbol{L}$ are the linear and angular momenta matrix: 


$$
\begin{aligned}
& P=\boldsymbol{m}(\boldsymbol{v}+\boldsymbol{w} \times \boldsymbol{r}) \\
& \boldsymbol{L}=\boldsymbol{I} \boldsymbol{w}+\boldsymbol{m} \boldsymbol{r} \times \boldsymbol{v}
\end{aligned}
$$

where $\boldsymbol{m}$ is the mass matrix and $\boldsymbol{I}$ is the inertial moment matrix; $\boldsymbol{v}$ is the translation velocity vector and $\boldsymbol{w}$ is the rotation velocity vector; $\boldsymbol{r}$ is the vector of center of mass relative to coordiante origin. The external loads $\boldsymbol{F}$ and $\boldsymbol{M}$ include aerodynamic load, hydrodynamic load, hydrostatic restoring force, and mooring restoring force

\subsection{Aerodynamics}

The aerodynamic load on the wind turbine is based on the blade element momentum (BEM) approach. For a floating wind turbine, the air inflow seen by the blade elements is unsteady so that the aerodynamic hysteresis will occur. The Stig Øye dynamic wake model (Øye, 1991) is used to model the hysteresis effect. Additionally, the Glauert correction and the Prandtl factor are included to correct the BEM model in the case of large induced velocity and finite blades.

\subsection{Hydrodynamics}

Hydrodynamic loads are estimated using the potential flow theory approach. The first order linear wave excitation forces are generated based on the linear impulse response function $\psi$

$$
\begin{aligned}
& F_{e x}^{1 s t}=\sum_{j=1}^{N} H^{1 s t}\left(\omega_{j}\right) \cdot \xi_{j} \cdot e^{i\left(\omega_{j} t+\varepsilon_{j}\right)} \\
& \xi_{j}=\sqrt{2 S\left(\omega_{j}\right) \Delta \omega}
\end{aligned}
$$

where is $\varepsilon_{j}$ the random phase of wave component $j . S$ is the wave spectrum.

In addition, the 2nd-order wave force is also modelled to capture the low-frequency response of the platform. The Newman approximation is used

$$
\begin{aligned}
& F_{e x}^{2 n d}(t)=\operatorname{Re}\left\{u^{2}+v^{2}\right\} \\
& u=\sum_{j=1}^{N} \sqrt{H^{2 n d}\left(\omega_{j}, \omega_{j}\right)} \operatorname{Re}\left\{\xi_{j} e^{i\left(\omega_{j} t+\varepsilon_{j}\right)}\right\} \\
& v=\sum_{j=1}^{N} \sqrt{H^{2 n d}\left(\omega_{j}, \omega_{j}\right)} \operatorname{Im}\left\{\xi_{j} e^{i\left(\omega_{j} t+\varepsilon_{j}\right)}\right\}
\end{aligned}
$$

The radiation wave force is calculated using a convolution model

$$
f_{\text {rad }}(t)=\int_{0}^{t} h(t-\tau) x(\tau) d \tau
$$

$h$ is known as the retardation function, which can be estimated by either the added mass or the potential damping. $x(t)$ is the velocity.

All the hydrodynamic coefficients used to build the numerical model are calculated in frequency domain using boundary element analysis software
Wadam (Veritas, 1994). The panel model is sketched in Figure 3.

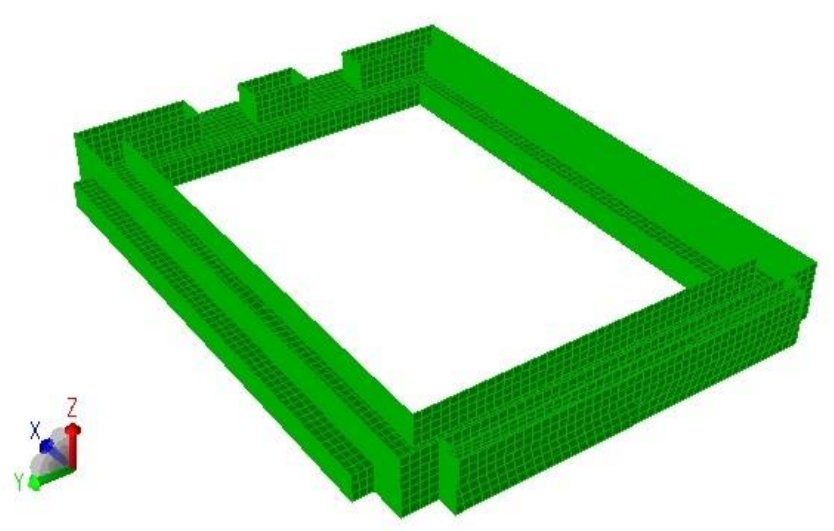

Figure 3. Panel model of the multi-purpose platform.

Due to the limitation of potential flow theory, no viscous drag force can be considered and the dynamic response will be overpredicted as a result. An additional drag force model is added to represent the viscous wave load acting on the platform. For translation motion (surge, heave, and pitch), a linear damping force model is used. On the contrary, a quadratic damping force model is employed for rotational motion (roll, pitch and, yaw)

The load effect of OWC wave energy converter can be represented by a linear force model. Assuming that the air is incompressible, the mass flow rate through the self-rectifying turbine (positive for air going outward) is

$$
\dot{m}=-\rho\left(\dot{x}_{1}-\dot{x}_{2}\right) S
$$

where $S$ is the sectional area of the chamber, $x_{1}$ is the wave elevation inside the WEC, $x_{2}$ is the heave motion of the WEC. Considering that Wells air turbine is employed, according to (Falcao and Henriques, 2016), the air pressure is given by

$$
p=\frac{\dot{m} \Omega}{K R}, K \approx 0.6803
$$

where $\Omega$ is the rotation speed of the air turbine and $R$ is the turbine's radius. Therefore, the load acting on the air turbine is

$$
\begin{aligned}
& f_{W E C}=p \cdot \pi R^{2} \\
& =-\frac{\rho\left(\dot{x}_{1}-\dot{x}_{2}\right) S \pi R \Omega}{0.6803}
\end{aligned}
$$

Assuming that $x_{1}$ is proportional to $x_{2}$, then the load effect of the WEC on the platform can be simplified as a linear damping force.

All the viscous damping coefficient is identified through the free-decay test carried out in the experiment.

\subsection{Structural dynamics}

Structural dynamics are considered based on nonlinear finite element method. The blades and the tower are modelled as nonlinear beam elements, while the mooring lines are represented by nonlinear bar ele- 
ments. The dynamic equations are solved in time domain by using the Newmark-b method. Structural damping is also included by applying the global Rayleigh damping for all flexible finite elements.

\subsection{Control strategy}

A variable-speed torque controller and a blade pitch controller are incorporated into the wind turbine, based on the DTU 10MW reference control algorithm (Bak et al., 2013). The two control systems are designed to work independently, for the most part, in the below-rated and above-rated wind speed range, respectively. The goal of the variable-speed torque controller is to maximize the power capture below the rated operation point. The blade-pitch controller is to regulate the generator power above the rated operation point.

\section{MODEL TEST}

The model test was performed in the wave basin at Centrale Nantes. The test model was scaled following the Froude scaling method (1/40th), as shown in Figure 4. This paper only presents an overview of the experiment setup here.

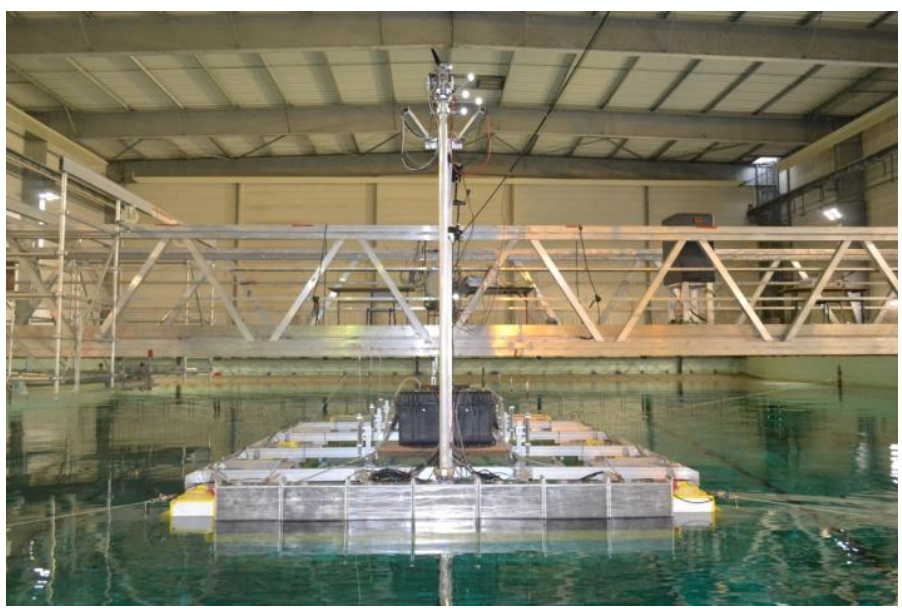

Figure 4. Model of the multi-purpose platform.

The power take-off (PTO) of the wave energy converters to be included in this wind-wave platform is first modelled using individual calibrated holes (Horel, 2019), as it is usually done when modelling OWC. In order to remove uncertainties associated with Reynolds effects on the blades, an experimental approach using real-time force control air turbine to simulate the thrust acting on at the nacelles was be adopted. During the test, the real-time platform motion recorded by the motion capture system is inputted into the controller, which calculates the rotor thrust force using FAST (Jonkman and Buhl Jr, 2005). The controller adjusts rotation speed of the fan to generate the desired thrust force. Such aerodynamic load modelling approach, as illustrated in
Figure 5, is known as the Hardware-in-Loop (HIL) approach. Please refer to (Horel, 2019) for the details of the HIL algorithm.
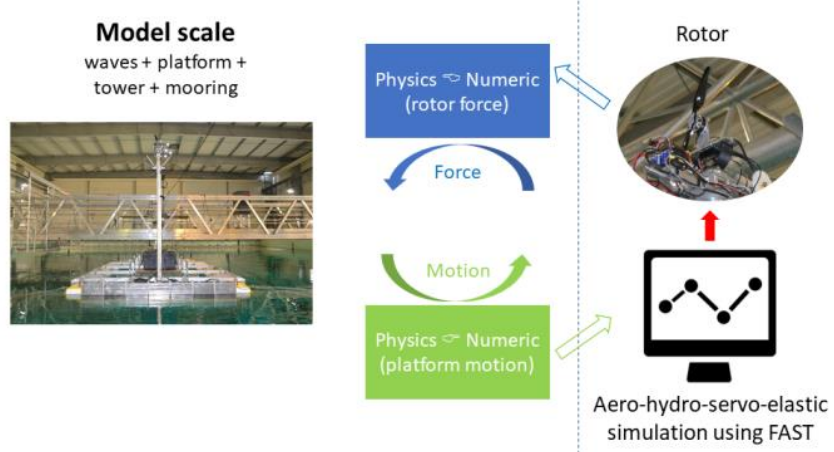

Figure 5. Aerodynamic load modelling algorithm.

The test model is moored using four aerial lines, which are made of springs, elastic rope and rigid Dyneema. The angle between each mooring line and $\mathrm{X}$-axis is $40 \mathrm{deg}$. The axial stiffness of each lines is adjusted to reach the target overall horizontal stiffness. The measured overall horizontal restoring stiffness is given in Table 3 .

Table 3 Mooring restoring stiffness.

\begin{tabular}{lll}
\hline DoF & Surge & Sway \\
\hline Stiffness & $464 \mathrm{kN} / \mathrm{m}$ & $335 \mathrm{kN} / \mathrm{m}$ \\
\hline
\end{tabular}

\section{CALIBRATION}

Prior to the validation, the numerical model is calibrated to ensure that the additional damping coefficient is an accurate representation of the real situation. In this research, $\boldsymbol{B}_{\text {platform }}$ and $\boldsymbol{B}_{W E C}$ are calibrated separately through free-decay test of the structure. In the experiment, two sets of free-decay test, WEC working and not working, were conducted enabling a separate identification of $\boldsymbol{B}_{\text {platform }}$ and $\boldsymbol{B}_{W E C}$.

In the first instance, damping coefficient of platform motion $\boldsymbol{B}_{\text {plafform }}$ is identified through free-decay test with the WEC not working. Subsequently, $\boldsymbol{B}_{\text {plat }}$ form is fixed and $\boldsymbol{B}_{W E C}$ is tuned manually until the simulated free-decay motion matches the experimental measurement (see Figure 6 and Figure 7). The final damping coefficients identified are listed in Table 4.

Table 4 Additional damping coefficient

\begin{tabular}{lll}
\hline & $\boldsymbol{B}_{\text {platform }}$ & $\boldsymbol{B}_{W E C}$ \\
\hline Surge & $3.5 \mathrm{E} 3 \mathrm{kN} \cdot \mathrm{s} / \mathrm{m}$ & $0 \mathrm{kN} \cdot \mathrm{s} / \mathrm{m}$ \\
Sway & $3.5 \mathrm{E} 3 \mathrm{kN} \cdot \mathrm{s} / \mathrm{m}$ & $0 \mathrm{kN} \cdot \mathrm{s} / \mathrm{m}$ \\
Heave & $1.0 \mathrm{E} 4 \mathrm{kN} \cdot \mathrm{s} / \mathrm{m}$ & $0.5 \mathrm{E} 4 \mathrm{kN} \cdot \mathrm{s} / \mathrm{m}$ \\
Roll & $2.0 \mathrm{E} 13 \mathrm{kN} \cdot \mathrm{s}^{2} \cdot \mathrm{m}$ & $0 \mathrm{kN} \cdot \mathrm{s} \cdot \mathrm{m}$ \\
Pitch & $2.6 \mathrm{E} 13 \mathrm{kN} \cdot \mathrm{s}^{2} \cdot \mathrm{m}$ & $0 \mathrm{kN} \cdot \mathrm{s} \cdot \mathrm{m}$ \\
Yaw & $5.0 \mathrm{E} 12 \mathrm{kN} \cdot \mathrm{s}^{2} \cdot \mathrm{m}$ & $0 \mathrm{kN} \cdot \mathrm{s} \cdot \mathrm{m}$ \\
\hline
\end{tabular}




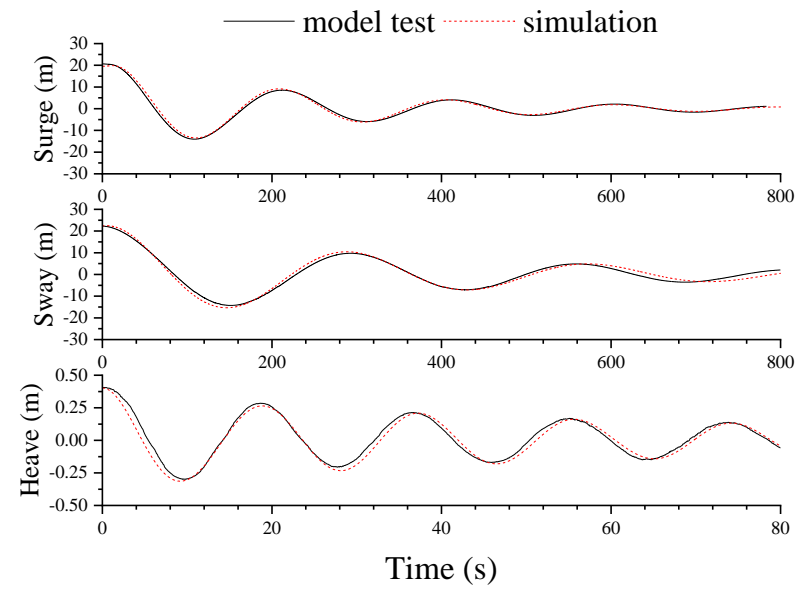

Figure 6. Translational free decay (WEC working).

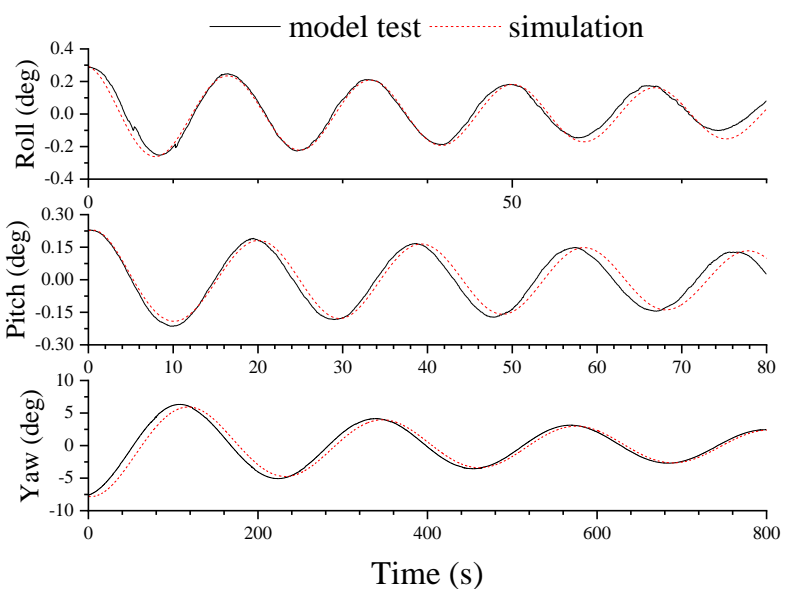

Figure 7. Rotational free decay (WEC working).

\section{VALIDATION}

\subsection{Random wave}

Given the identified additional damping coefficients, the prediction capacity of the developed numerical model is validated under random waves in the first instance. The record duration in the experiment is around $10 \mathrm{mins}$, corresponding to $3800 \mathrm{~s}$ for full scale. Accordingly, the numerical simulation is set to 3800 s. For both experimental measurement and numerical simulation results, only the last $3600 \mathrm{~s}$ data are used for analysis so as to eliminate the transient response. All the validations are presented at full-scale.

Table 5 Statistics of platform global motions $\left(H_{s}=2 \mathrm{~m}, T_{p}=18\right.$ s).

\begin{tabular}{|c|c|c|c|c|c|}
\hline & & Max & Min & Mean & Std. dev \\
\hline \multirow{2}{*}{$\begin{array}{c}\text { Surge } \\
\text { (m) }\end{array}$} & Experiment & 1.20 & 0.22 & 0.21 & 0.31 \\
\hline & Sim & 1.45 & 0.24 & 0.26 & 0.35 \\
\hline \multirow{2}{*}{$\begin{array}{c}\text { Heave } \\
\text { (m) }\end{array}$} & Expe & 0.92 & -1.21 & -0.01 & 0.35 \\
\hline & & 1.08 & -1.10 & 0.00 & 0.33 \\
\hline \multirow{2}{*}{$\begin{array}{l}\text { Pitch } \\
\text { (deg) }\end{array}$} & & 1.24 & -1.10 & -0.01 & 0.38 \\
\hline & Simulation & 1.20 & -1.15 & 0.00 & 0.37 \\
\hline
\end{tabular}

Figure 8 plots the simulated and measured platform global motions over 1-hour period whilst the corresponding statistics are summarized in Table 5.

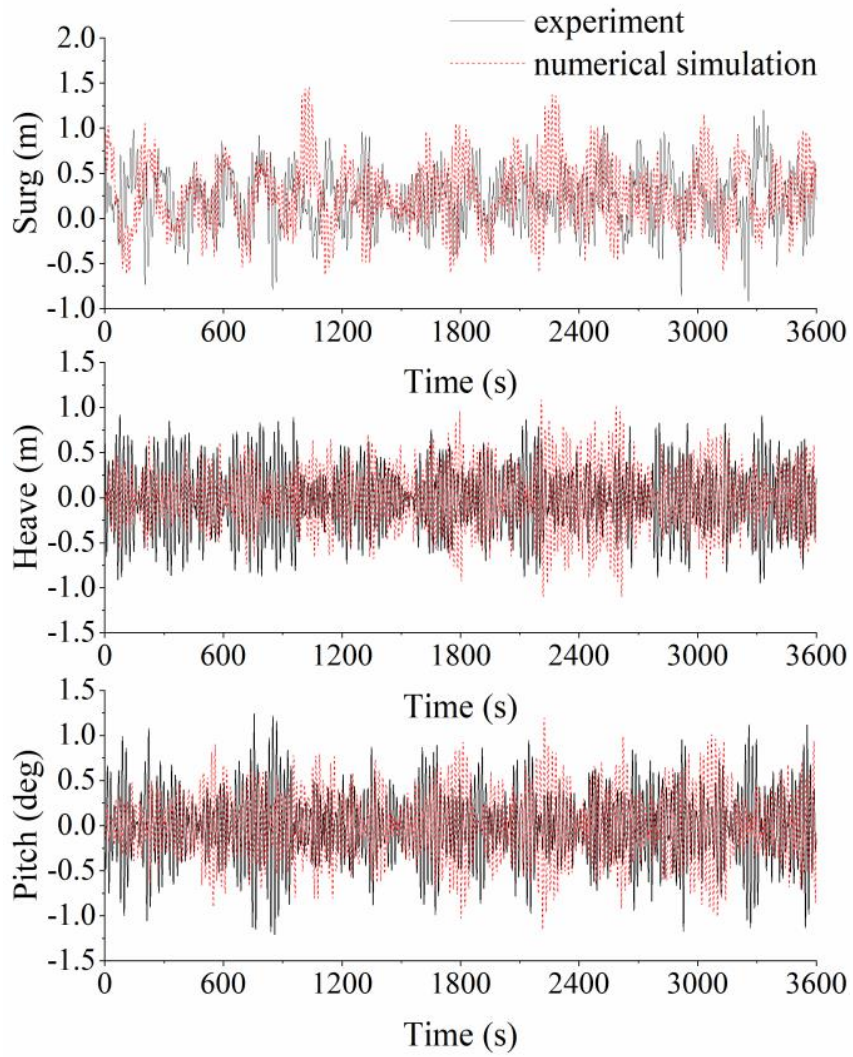

Figure 8 . Times series of platform global motions $\left(H_{s}=2 \mathrm{~m}, T_{p}\right.$ $=18 \mathrm{~s})$.
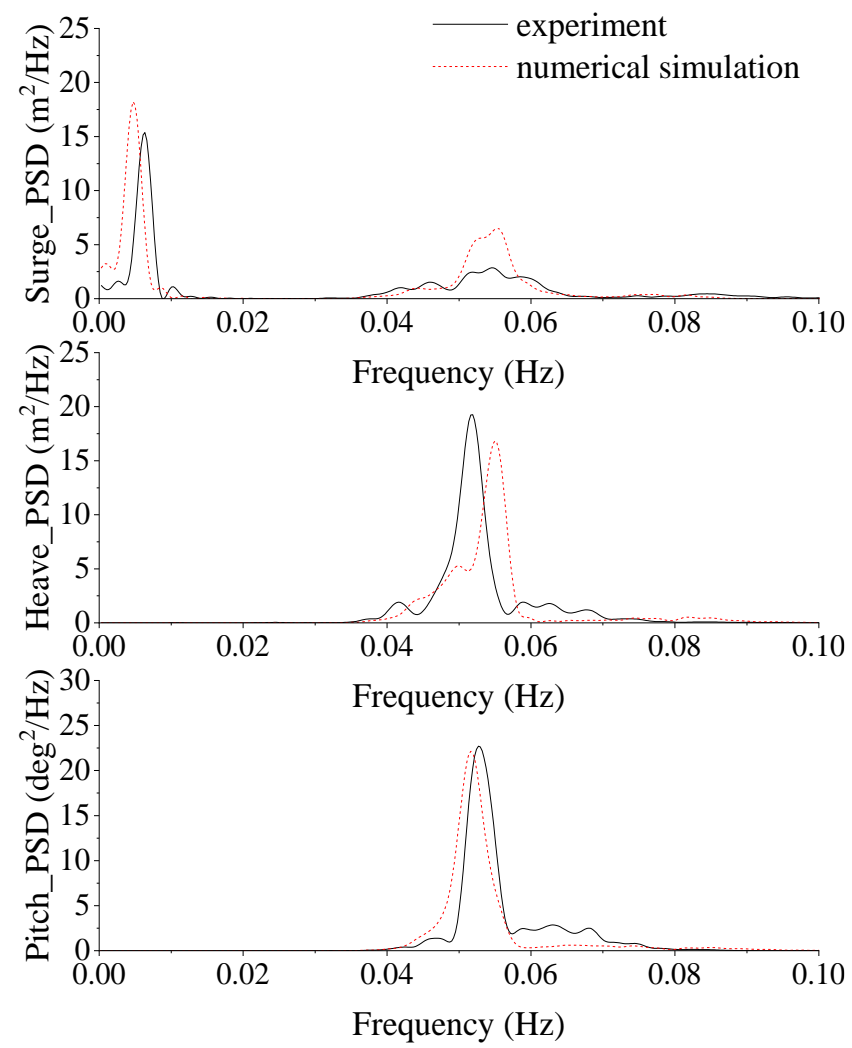

Figure 9. PSD of platform global motions $\left(H_{s}=2 \mathrm{~m}, T_{p}=18 \mathrm{~s}\right)$.

The platform global motions are further analyzed through spectral analysis and the results are present- 
ed in Figure 9. In general, an overall consistency between model test and numerical simulation is observed. Both heave and pitch motions are primarily induced around wave frequency range due to the first order linear wave excitation force. A noticeable feature of surge power spectrum density (PSD) is that low-frequency response dominates surge. The low-frequency drift motion is induced by second order nonlinear wave force.

The ability of the numerical model to accurately simulate the structural loads is also assessed. Figure 10 plots the PSD of tower base fore-aft bending moment. The plot shows that the structural dynamics is captured by the numerical model accurately, although slight discrepancy is still observed. The tower base bending moment response is very similar to platform pitch motion, with the response excited around peak period of the incident wave. It inherently implies that the bending moment is mainly induced by pitch motion.

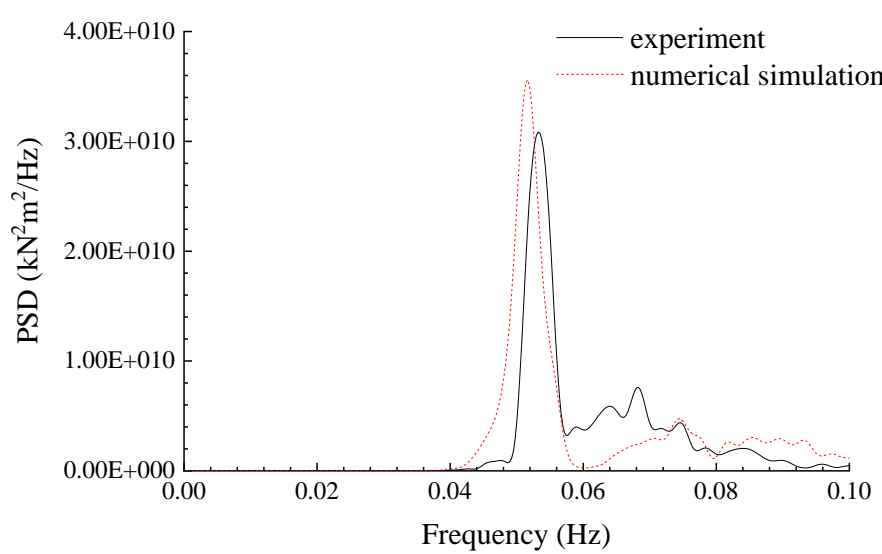

Figure 10. PSD of tower base fore-aft bending moment $\left(H_{s}=2\right.$ $\left.\mathrm{m}, T_{p}=18 \mathrm{~s}\right)$.

\subsection{Random wave and uniform wind}

The PSD of platform global motions and tower base loads in wind \& wave condition is presented in Figure 11 , in which the wind turbine is operational and the wind turbine controller is active. The statistics of platform global motions are given in Table 6. Generally, the agreement between experiment and numerical simulation is good.

Table 6 Statistics of platform global motions $\left(V=8 \mathrm{~m} / \mathrm{s}, H_{s}=2\right.$ $\left.\mathrm{m}, T_{p}=18 \mathrm{~s}\right)$

\begin{tabular}{|c|c|c|c|c|c|}
\hline & & $\operatorname{Max}$ & Min & Mean & Std. dev \\
\hline \multirow{2}{*}{$\begin{array}{c}\text { Surge } \\
\text { (m) }\end{array}$} & Experiment & 2.98 & 0.75 & 1.94 & 0.32 \\
\hline & Simulation & 3.82 & 0.88 & 2.26 & 0.44 \\
\hline \multirow{2}{*}{$\begin{array}{c}\text { Heave } \\
\text { (m) }\end{array}$} & Experiment & 0.92 & -0.95 & -0.01 & 0.35 \\
\hline & Simulation & 1.18 & -1.21 & 0.00 & 0.33 \\
\hline \multirow{2}{*}{$\begin{array}{l}\text { Pitch } \\
\text { (deg) }\end{array}$} & Experiment & 1.25 & -1.21 & 0.00 & 0.38 \\
\hline & Simulation & 1.28 & -1.19 & 0.02 & 0.37 \\
\hline
\end{tabular}

The comparison between Figure 9 and Figure 11 indicates that wind load effect on platform motion is not significant, particularly for heave and pitch motions as the thrust force is applied horizontally. Surge motion is increased, but slightly.
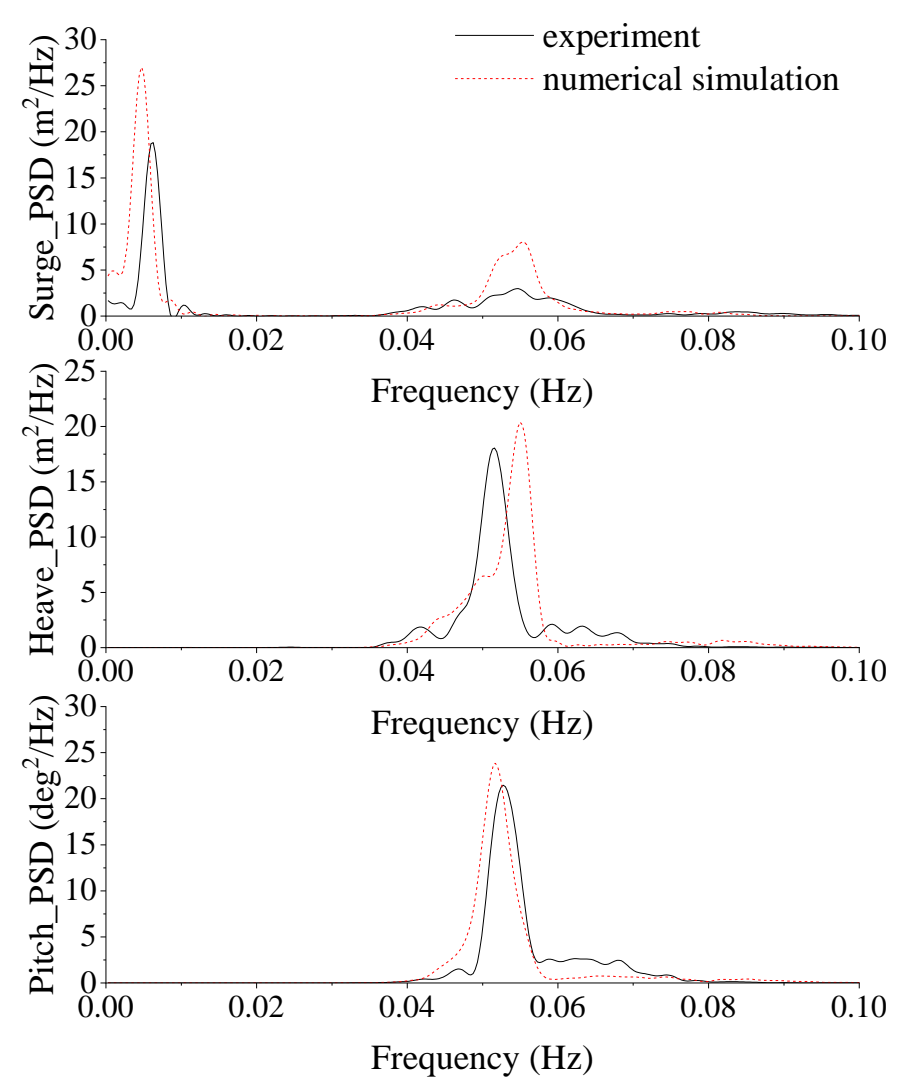

Figure 11. PSD of platform global motions $\left(V=8 \mathrm{~m} / \mathrm{s}, H_{s}=2\right.$ $\left.\mathrm{m}, T_{p}=18 \mathrm{~s}\right)$.

The simulated tower base bending moment is compared to the experiment data in Figure 12, which confirms a reliable prediction ability of the numerical model

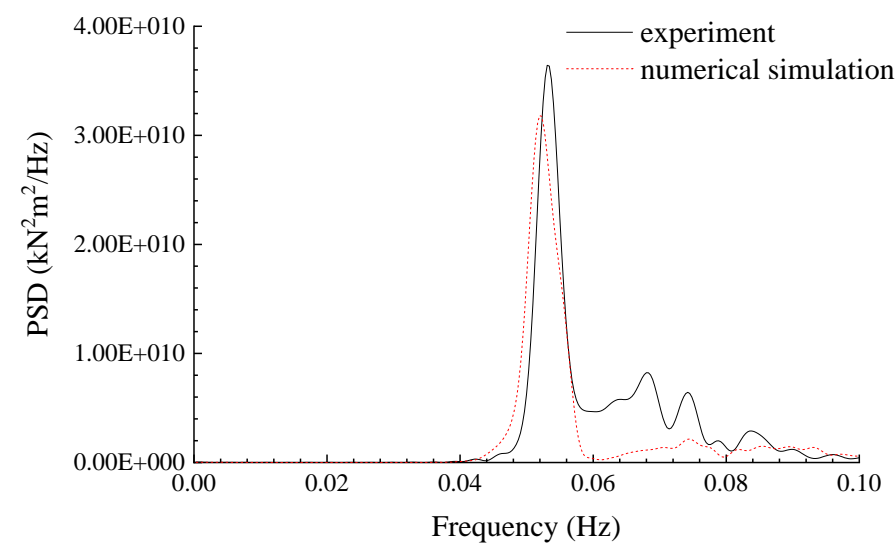

Figure 12. PSD of tower base fore-aft bending moment $(V=8$ $\left.\mathrm{m} / \mathrm{s}, H_{s}=2 \mathrm{~m}, T_{p}=18 \mathrm{~s}\right)$.

\section{CONCLUSIONS}

The development and validation of a numerical model for the coupled aero-hydro-servo-elastic analysis of the Blue Growth Farm multi-purpose offshore platform are presented. 
The numerical model employs state-of-art approaches to simulate wind turbine aerodynamics, hydrodynamics, structural dynamics as well as the couplings between them. Model test research has been launched and the experiment data are used to validate the numerical model.

The aero-hydro-servo-elastic coupled model is validated for typical load cases. Overall consistency with model test data is confirmed, indicating that the coupled numerical model could be used for further analysis of the Blue Growth Farm multi-purpose platform.

\section{ACKNOWLEDGMENT}

This work has been produced in the framework of the Blue Growth Farm project (http://www.thebluegrowthfarm.eu/), which has received funding from the European Union's Horizon 2020 research and innovation programme under Grant Agreement number 774426. The content of the work does not report the opinion of the European Commission and reflects only the views of the author(s), including errors or omissions. The European Commission is also not liable for any use that may be made of the information contained herein.

\section{REFERENCES}

BAK, C., ZAHLE, F., B., R., K., T., Y., A., C.H., L., N., A. \& HANSEN, M. H. 2013. Description of the DTU $10 \mathrm{MW}$ Reference Wind Turbine.

HOERL B., 2019. Results of the indoor experimental activities report. Blue Growth Farm project report D3.3.

EUROPEAN COMMISSION, D. M. 2012. Blue Growth-Scenarios and drivers for Sustainable Growth from the Oceans, Seas and Coasts. Rotterdam/Brussels.

FALCAO, A. F. O. \& HENRIQUES, J. C. C. 2016. Oscillating-water-column wave energy converters and air turbines: A review. Renewable Energy, 85, 1391-1424.

H2OCEAN. 2012. H2Ocean [Online]. http://www.h2ocean-project.eu/. [Accessed 28 December 2019].

JONKMAN, J. M. \& BUHL JR, M. L. 2005. FAST User's Guide. National Renewable Energy Laboratory (NREL).

LAGASCO, F., VASSALLI, F., PENNINO, R., GENTILE, G., FIACCO, L. \& G. URBANO, P. 2019. New engineering approach for the development and demonstration of a multipurpose platform for the blue growth economy. 38th International Conference on Ocean, Offshore and Arctic Engineering, 2019 Glasgow, UK.
LI, L., CHENG, Z. S., YUAN, Z. M. \& GAO, Y. 2018a. Short-term extreme response and fatigue damage of an integrated offshore renewable energy system. Renewable Energy, 126, 617-629.

LI, L., COLLU, M., RUZZO, C., FAILlA, G., ABHINAV, K. A. \& ARENA, F. 2019. Analysis of the coupled dynamics of an offshore floating multi-purpose platform, Part A: rigid body analysis. 38th International Conference on Ocean, Offshore and Arctic Engineering, June 9-14 2019a Glasgow, Scotland.

LI, L., GAO, Y., HU, Z. Q., YUAN, Z. M., DAY, S. \& LI, H. R. 2018b. Model test research of a semisubmersible floating wind turbine with an improved deficient thrust force correction approach. Renewable Energy, 119, 95-105.

LI, L., GAO, Y., YUAN, Z. M., DAY, S. \& HU, Z. Q. 2018c. Dynamic response and power production of a floating integrated wind, wave and tidal energy system. Renewable Energy, 116, 412-422.

LI, L., YUAN, Z.-M., GAO, Y., ZHANG, X. \& TEZDOGAN, T. 2019b. Investigation on long-term extreme response of an integrated offshore renewable energy device with a modified environmental contour method. Renewable Energy, 132, 33-42.

MALARA, G., ROMOLO, A., FIAMMA, V. \& ARENA, F. 2017. On the modelling of water column oscillations in U-OWC energy harvesters. Renewable Energy, 101, 964-972.

MERMAID. 2014. MERMAID [Online]. http://www.vliz.be/projects/mermaidproject/i ndex.html [Accessed 28 December 2019].

MULIAWAN, M. J., KARIMIRAD, M. \& MOAN, T. 2013. Dynamic response and power performance of a combined Spar-type floating wind turbine and coaxial floating wave energy converter. Renewable Energy, 50, 47-57.

MUSES. 2016. MUSES [Online]. https://musesproject.com/. [Accessed 18 December 2019].

$\varnothing Y E$, S. Dynamic stall simulated as time lag of separation. Proceedings of the 4th IEA Symposium on the aerodynamics of wind turbines, 1991.

RUZZO, C., FAILLA, G., ARENA, F., M.COLLU, LI, L. \& MARIOTTI, A. 2019. Analysis of the coupled dynamics of an offshore floating multi-purpose platform, Part B: hydro-elastic analysis with flexible support platform. 38th International Conference on Ocean, Offshore and Arctic Engineering, June 9-14 2019 Glasgow, Scotland.

SPACE@SEA. 2017. Space@Sea [Online]. https://spaceatsea-project.eu/. [Accessed].

TROPOS. 2012. Tropos [Online 18 December 2019]. $\quad$ http://www.troposplatform.eu/. [Accessed 18 December 2019]. 
VERITAS, D. N. 1994. WADAM-Wave Analysis by Diffraction and Morison Theory. SESAM user's manual, Høvik.

WAN, L., GAO, Z., MOAN, T. \& LUGNI, C. 2016. Experimental and numerical comparisons of hydrodynamic responses for a combined wind and wave energy converter concept under operational conditions. Renewable Energy, 93, 87-100. 